\title{
A WEIGHTED HARDY-TYPE INEQUALITY \\ FOR $0<p<1$ WITH SHARP CONSTANT
}

\section{Noureddine Azzouz, Victor I. Burenkov And AbDelKader Senouci}

Abstract. Hardy-type inequalities with sharp costants for $0<p<1$ for power weight functions were established in [10], [5]. In this work, we give an extension of these inequalities for general weight functions, prove the existence of extremal functions and write them out explicitly.

Mathematics subject classification (2010): 35J20, $35 \mathrm{~J} 25$.

Keywords and phrases: Hardy operator, weighted $L_{p}$-spaces with $0<p<1$.

\section{REFERENCES}

[1] J. Bergh, V. Burenkov, L.-E. Persson, Best constants in reversed Hardy's inequalities for quasimonotone functions, Acta Sci. Math. (Szeged) 59 (1994), no. 1-2, 221-239.

[2] J. Bergh, V. Burenkov, L.-E. Persson, On some sharp reversed Hölder and Hardy-type inequalities, Math. Nachr. 169 (1994), 19-29.

[3] V. I. Burenkov, Function spaces. Main integral inequalities related to $L_{p}$-spaces, Peoples' Friendship University of Russia, Moscow, 1989, 96 pp. (in Russian).

[4] V. I. Burenkov, On the exact constant in the Hardy inequality with $0<p<1$ for monotone functions, Trudy Matem. Inst. Steklov. 194 (1992), 58-62 (in Russian); English translation in Proc. Steklov Inst. Math. 1993, no. 4 (194), 59-63.

[5] V. I. Burenkov, A. Senouci, T. V. Tararykova, Hardy-type inequality for $0<p<1$ and hypodecreasing functions, Eurasian Math. J. 1, no. 3 (2010), 27-42.

[6] A. GogatishVili, V. D. Stepanov, Reduction theorems for weighted integral inequalities on the cone of monotone functions, Russian Math. Surveys, 68, no. 4 (2013), 597-664.

[7] A. Kufner, L. Maligranda, L.-E. Persson, The Hardy inequality. About its history and some related results, Vydavatelsky Servis Publishing House, Pilsen, 2007, 162 pp.

[8] A. Kufner, L.-E. Persson, Weighted inequalities of Hardy type, World Scientific, New JerseyLondon-Singapore-Hong Kong, 2003, xviii+357 pp.

[9] SH. LAI, Weighted norm inequalities for general operators on monotone functions, Trans. Amer. Math. Soc. 34, no. 2 (1993), 811-836.

[10] A. Senouci, T. V. TARARYKova, Hardy-type inequality for $0<p<1$, Evraziiskii Matematicheskii Zhurnal (2008), no. 2, 111-115. 